\section{Young Male With Myocarditis Following mRNA-1273 Vaccination Against Coronavirus Disease-2019 (COVID-19)}

Kohei Kaneta, MD; Kensuke Yokoi, MD; Kota Jojima, MD; Norihiko Kotooka, MD, PhD; Koichi Node, MD, PhD

I $\mathrm{n}$ Japan, the introduction of the coronavirus disease-2019 (COVID-19) vaccine has been gradually expanded to younger people, but concerns about myocarditis associated with the vaccine among young people have been reported. We report a typical case of a young man with myocarditis following administration of an mRNA-1273 COVID-19 vaccine (Moderna).

A 25-year-old man with no past medical or allergic history, developed a fever after receiving the second vaccination. On the 3rd day, he was admitted to hospital with chest pain. The ECG on admission showed ST elevation in the inferior and lateral leads (Figure A), and blood tests showed elevation of myocardial enzymes, which peaked $12 \mathrm{~h}$ after the onset of symptoms (creatine kinase (CK) $604 \mathrm{U} / \mathrm{I}, \mathrm{CK}-\mathrm{MB} 47 \mathrm{ng} / \mathrm{mL}$ and troponin T $0.725 \mathrm{ng} / \mathrm{mL}$ ). Transthoracic echocardiography showed inferolateral hypokinesia (Figure B), coronary angiography showed no significant stenosis, and left ventriculography showed posterolateral hypokinesia (Figure C, Supplementary Movie). Cardiac magnetic resonance (CMR) showed regional increase of T2 signal intensity and late gadolinium enhancement (LGE) of the posterolateral wall (Figure D), findings that met the updated Lake Louise criteria. ${ }^{1}$ His ECG and echocardiographic findings normalized over several days, and the chest pain spontaneously improved without treatment during hospitalization. The patient was discharged on the 9th day after admission. The stable clinical course and CMR findings were consistent with previous reports in other countries. $^{2}$

\section{Disclosures}

K.N. is a member of Circulation Journal's Editorial Team. The authors declare no conflicts of interest.

\section{References}

1. Ferreira VM, Schulz-Menger J, Holmvang G, Kramer CM, Carbone I, Sechtem U, et al. Cardiovascular magnetic resonance in nonischemic myocardial inflammation: Expert recommendations. J Am Coll Cardiol 2018; 72: 3158-3176.

2. Patel YR, Louis DW, Atalay M, Agarwal S, Shah NR. Cardiovascular magnetic resonance findings in young adult patients with acute myocarditis following mRNA COVID-19 vaccination: A case series. J Cardiovasc Magn Reson 2021; 23: 101.

\section{Supplementary Files}

Supplementary Movie. Left ventriculography showing posterolateral hypokinesia.

Please find supplementary file(s);

http://dx.doi.org/10.1253/circj.CJ-21-0818

Received September 22, 2021; revised manuscript received September 26, 2021; accepted September 29, 2021; J-STAGE Advance Publication released online November 6, 2021 Time for primary review: 4 days

Department of Cardiovascular Medicine, Saga University, Saga, Japan Mailing address: Kensuke Yokoi, MD, Department of Cardiovascular Medicine, Saga University, 5-1-1 Nabeshima, Saga 849-8501, Japan. E-mail: kensukey0709@gmail.com

All rights are reserved to the Japanese Circulation Society. For permissions, please e-mail: cj@j-circ.or.jp

ISSN-1346-9843
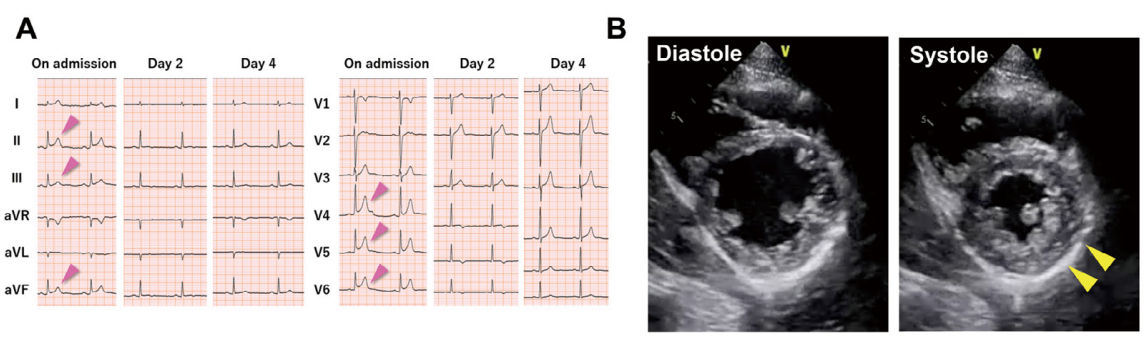

C

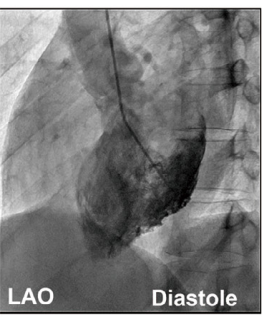

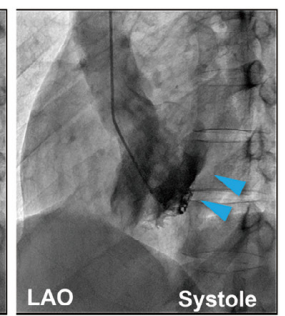

D
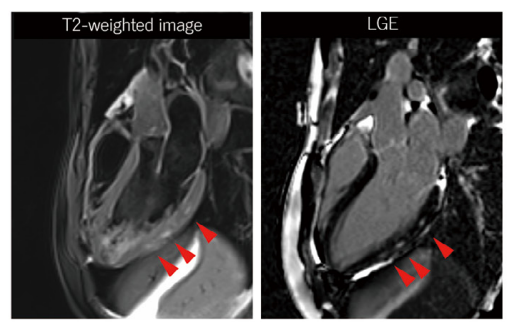

Figure. (A) ECG on admission and serial changes until normalization. ST elevation can be seen in several leads (pink arrowheads). (B) Transthoracic echocardiography showing posterolateral hypokinesia (yellow arrowheads). (C) Left ventriculography showing posterolateral hypokinesia (blue arrowheads). (D) CMR showing regional increase of T2 signal intensity and LGE of the posterolateral segment (red arrowheads). 